2 Review

\title{
4 Experimental therapies of Mycobacterium abscessus infections
}

5 Michal Meir ${ }^{1}$ and Daniel Barkan ${ }^{2, \#}$

61 Pediatric Infectious Diseases Unit, The Ruth Rappaport Children's Hospital, Rambam Health-Care

7 Campus, Haifa, Israel. MI_MEIR@rambam.health.gov.il

$8{ }^{2}$ Koret School of Veterinary Medicine, The Robert H. Smith Faculty of Agriculture, Food and

9 Environment, The Hebrew University of Jerusalem, Rehovot, Israel.

10 \# Corresponding Author: daniel.barkan@mail.huji.ac.il. Tel: +972-8-9489065

11 Keywords: Mycobacterium abscessus, drug treatment, experimental therapy, review.

12 Received date:

13

14

15

16

17

18

19 


\section{Abstract}

22 Mycobacterium abscessus is a non-tuberculous mycobacteria notoriously known for causing

23 severe, chronic infections. Treatment of these infections is challenging due to either intrinsic or

24 acquired resistance of $M$. abscessus to multiple antibiotics. Despite prolonged poly-antimicrobial

25 therapy, treatment of $M$. abscessus infections often fails, leading to progressive morbidity and

26 eventual mortality. Great research efforts are invested in finding new therapeutic options for $M$.

27 abscessus. Clofazimine and rifabutin are known anti-mycobacterial antibiotics, repurposed for

28 use against $M$. abscessus. Novel antimicrobials active against $M$. abscessus include delamanid,

29 pretomanid and PIPD1 and the recently approved beta-lactamase inhibitors avibactam,

30 relebactam and vaborbactam. Previously unused antimicrobial combinations e.g. vancomycin-

31 clarithromycin and dual beta-lactam therapy have been shown to have synergistic effect against

32 M. abscessus in experimental models, suggesting their possible use in multiple-drug regimens.

33 Finally, engineered phage therapy has been reported to be clinically successful in a severe case

34 of disseminated $M$. abscessus infection. While many of these experimental therapeutics have

35 shown activity against $M$. abscessus in vitro, as well as intracellular and/or animal models, most

36 have little if any evidence of effect in humans infections. Clinical studies of $M$. abscesssus

37 treatments are needed in order to reliably determine the value of their incorporation in

38 therapeutic regimens. 


\section{Introduction}

44 Non-tuberculous mycobacteria (NTM) are ubiquitous environmental organisms being 45 increasingly recognized as human pathogens, with rising incidence of infections (1). Of NTMs 46 isolated, Mycobacterium abscessus is associated with the most severe infections including

47 progressive pulmonary disease, skin and soft tissue, central nervous system and disseminated, 48 often fatal disease.

49 Treatment of $M$. abscessus infections is remarkably challenging. M. abscessus is intrinsically 50 resistant to multiple antimicrobials including the anti-tuberculous drugs, and macrolide 51 resistance in the subspecies abscessus (1). In addition, the chronic nature of M. abscessus 52 infections, as well as prolonged sub-lethal concentrations of antimicrobials, drives induced 53 (mutation based) antibiotic resistance, further limiting antibiotic choices and requiring multi54 antimicrobial therapy.

55 There is growing evidence that specific $M$. abscessus genotypes are associated with distinct 56 antimicrobial resistance patterns - erm (41) and $r r l$ gene mutations with macrolide resistance, 57 rrs gene mutations with amikacin resistance, and gyrA and $g y r B$ with quinolone resistance $(2,3)$.

58 Genetic susceptibility patterns are now increasingly recognized as predictors of antibiotic effect 59 versus failure, therefore guiding choice of antimicrobial drugs, especially macrolides and 60 aminoglycosides (4).

61 Current recommendations for treatment of $M$. abscessus pulmonary infections include 62 combination therapy of two or more intravenous drugs (i.e. amikacin, tigecycline, imipenem and 63 cefoxitin) with one or two oral antimicrobials including macrolides, linezolid, clofazimine and 
64 occasionally, a quinolone. Although choice of antimicrobials is generally guided by in vitro

65 susceptibility testing, data on the effect of combination treatments is scarce, and correlation with

66 clinical effect is limited (5). Prolonged multi-antimicrobial therapy is often limited by drug-

67 induced toxicity, yet even under strict regimens, treatment failure rates remain high with

68 recurrent or chronic infections and grave clinical outcome. In accordance with the search for new

69 therapeutics, there is a surge in the number of experimental antibiotics with potential activity

70 against $M$. abscessus in various mechanisms. This review summarizes evidence of novel and

71 experimental therapeutic options for treatment of $M$. abscessus infections. These include novel

72 antibiotics, new - and sometimes counter-intuitive - antibiotic combinations, re-purposing of

73 known antibiotics, and phage therapy.

\section{Clofazimine}

75 Clofazimine is a fat-soluble riminophenazine dye that was developed in the 1950s, mainly for treating leprosy, and found to have antibiotic activity against M. abscessus isolates. Several

77 studies have shown in vitro synergy between clofazimine and other antibiotics, such as

78 clarithromycin, amikacin, tigecycline and bedaquiline (BDQ)(6-9), while other studies report

79 possible promotion of resistance (6). Clinical data on the efficacy of clofazimine is available yet

80 limited. In a recent retrospective report of 42 patients with $M$. abscessus pulmonary infection,

81 sputum culture conversion was achieved in $43 \%$ of cases following combination treatment that

82 initially included clofazimine, and in $15 \%$ of non-responsive cases (cases in which previous

83 antibiotic treatments failed)(10). Another cohort study demonstrated favorable outcomes using

84 clofazimine to treat $M$. abscessus pulmonary infection in immune-compromised hosts, yet 85 included only a small numbers of patients (11). Current clinical treatment guidelines recommend 86 clofazimine as a preferred drug for treatment of $M$. abscessus pulmonary infection, although its 
87 practical use may be limited by limited availability in many countries, including in the United

88 States $(1,5)$.

89 Bedaquiline

90

91

92

93

94

95

96

97

98

99

100

101

102

103

104

105 106

107

Bedaquiline (BDQ; code names TMC2017 and R207910) is a diarylquinoline antibiotic. In Mycobacterium tuberculosis it was shown to act through inhibition of the ATP Synthase (12), which is considered true in other mycobacteria as well. It is now recommended by the WHO for use as a part of an antibiotic-combination regimen for multidrug resistant tuberculosis (13). Reports on in vitro efficacy of BDQ on clinical isolates of $M$. abscessus $(14,15)$ showed most isolates to be have an MIC to BDQ ranging $0.016-1 \mathrm{mg} / \mathrm{L}$, yet a substantial proportion (15\% of isolates) had MICs of $16 \mathrm{mg} / \mathrm{L}$ and more. Preclinical in vivo models of $M$. abscessus infection showed variable results. In nude mice infected with the reference strain ATCC 19977, BDQ had no effect on survival or on mycobacteria load (16), while in a $\mathrm{GKO}^{-/}$mice, SCID mice and zebrafish models, BDQ had a protective clinical effect $(9,17)$.

There is scant data on the clinical effect of BDQ in humans infected with M. abscessus, although current reports are somewhat encouraging, namely showing a tolerable safety profile in a multidrug regimen (18). However, given a report of an antagonistic effect of bedaquiline with $\beta$ lactams (19), caution is warranted when considering this treatment combination.

\section{Rifabutin}

The rifamycin rifabutin, has been recently shown to have in vitro activity against reference strains as well as clinical isolates of $M$. abscessus. This antimicrobial activity was approximately 10-fold greater than the activity rifampin and rifapentine, and was evident in clarithromycin- 
108

109

110

111

112

113

114

115

116

117

118

119

120

121 unaffected by BlaMab (25).

122

123

124

125

126 127 cefepime, ceftaroline, and cefuroxime) in M. abscessus clinical isolates. With the exception of 128

resistant strains $(20,21)$. Unfortunately no pre-clinical in vivo or clinical data is available on its use in $M$. abscessus infection.

\section{Novel $\beta$-lactamase inhibitors}

Resistance of $M$. abscessus to $\beta$-lactams is mediated by multiple mechanisms, including a chromosomally-encoded Ambler-Class A $\beta$-lactamase (Blamab), which is not inhibited by clavulonate, tazobactam or sulbactam (22). The possible activity of newly developed $\beta$ lactamase inhibitors has been examined in several recently published studies. Avibactam is a non $\beta$-lactam $\beta$-lactamase inhibitor approved in combination with ceftazidime for treating gramnegative bacterial infections. Unlike clavulonate and tazobactam, avibactam appears to inhibit Bla $a_{\text {ab }}$ (23). Combining avibactam with amoxicillin or with piperacillin was shown to be effective against $M$. abscessus reference strains and clinical isolates, as well as in vivo in zebrafish and Galleria mellonella models, respectively $(23,24)$. Surprisingly, avibactam was also found to improve the in vitro and in vivo effect of imipenem, a carbapenem supposedly

\section{unaffected by Blamab (25).}

Relebactam and Vaborbactam are other non- $\beta$ lactam, $\beta$-lactamase inhibitors recently approved for use in the combinations imipenem-relebactam and meropenem-vaborbactam. Relebactam was shown to inhibit Blamab, and rendered clinical $M$. abscessus isolates susceptible to amoxicillin (26). Another study examined the effect of relebactam and vaborbactam on the MIC of several carbapenems, (including imipenem and meropenem) and cephalosporins (including cefoxitin, the MICs of all antibiotics tested decreased in the presence of either relebactam or vaborbactam, suggesting a possible benefit to their use as a part of a $\beta$-lactam based combination (27). Unfortunately, no clinical studies are yet available to assess the efficacy of avibactam, 
131 relebactam or vaborbactam in treatment combinations for $M$. abscessus infections. Also, all the

132 novel $\beta$-lactamase inhibitors are currently clinically available only as parts of a fixed ratio drug 133 combination with $\beta$-lactams. As both drug-ratio and choice of $\beta$-lactams may not be optimal for 134 treating $M$. abscessus, clinical use of the novel $\beta$-lactamase inhibitors for this purpose may be 135 complicated.

\section{Dual $\beta$-lactams}

137 The pharmacological principle of using two $\beta$-lactams is based on the selective or relatively 138 selective inhibition of non-redundant target enzymes in mycobacterial physiology. $\beta$-lactams act

139 by inhibiting transpeptidases essential for the biosynthesis of the bacterial cell-wall. It is now 140 evident that while most bacteria utilize mostly D,D-transpeptidases (also known as penicillin 141 binding proteins), mycobacteria rely considerably on L,D-transpeptidases. As various $\beta$-lactams 142 exert different inhibitory activity on different L,D-transpeptidases and on D,D-transpeptidases, 143 the combination of two $\beta$-lactams may have a synergistic effect (28). Avibactam may also 144 directly inhibit L,D-transpeptidases (29), which may explain why its addition to imipenem is 145 more effective then imipenem alone. Several dual- $\beta$-lactam combinations have indeed shown 146 synergy against clinical isolates in vitro, i.e. imipenem with cefoxitin or with cefdinir, as well as 147 with avibactam (30). Similar synergy was shown in a murine chronic pulmonary infection model 148 (31). Unfortunately, no clinical trials of dual- $\beta$ lactam therapy in $M$. abscessus treatment are 149 available. However, these studies suggest that using two $\beta$-lactam agents in a therapeutic multi150 drug regimen may be of benefit rather than redundant.

\section{Vancomycin/clarithromycin}


152 Vancomycin is a tricyclic glycopeptide antibiotic commonly used against Gram-positive

153 bacteria, yet considered ineffective against mycobacteria. Surprisingly, vancomycin was shown

154 to exhibit synergism with clarithromycin against $M$. abscesseus strains that were initially 155 susceptible to clarithromycin (32). In strains in which clarithromycin resistance was 156 experimentally induced, the addition of vancomycin lowered the MICs to clarithromycin.

157 Conversely, following prolonged exposure to clarithromycin, clinically relevant clarithromycin 158 MICs were not reached, even with the addition of vancomycin, suggesting cautious interpretation 159 when applying this in vitro study to clinical practice (32). Considering the side effects of 160 prolonged vancomycin treatment, the need for parenteral administration, and the concern for 161 emerging vancomycin-resistant bacteria, clinical use of this combination is deferred pending 162 further evidence.

\section{Novel antimicrobials}

164 Omadacycline, a novel aminomethylcycline antimicrobial agent and a member of the tetracycline 165 class of drugs, was recently approved by the FDA for treatment of skin and soft tissue infections 166 and pneumonia (33). Eravacycline (a fluorocycline) is a new tetracycline analog approved for the 167 parenteral treatment of complicated intraabdominal infections (34). In vitro studies have shown 168 both omadacycline and eravacycline to have similar antimicrobial activity to tigecycline against 169 both reference and clinical $M$. abscessus strains $(33,35,36)$. Specifically as omadacycline is 170 available as an oral formulation $(37,38)$, it may have a role in treating chronic M. abscessus 171 infections in outpatient settings. Treatment of chronic $M$. abscessus pulmonary infection has 172 been recently reported in one patient, with good tolerability and some clinical benefit (39). No 173 other clinical trials describing the use of omadacycline or eravcycline in $M$. abscessus infections 174 are available. 
175 Tedizolid is a next-generation oxazolidinone antibiotic approved in 2014 by the FDA for 176 treatment of skin and soft tissue infections (40). Several in vitro studies have demonstrated

177

178

179

180

181

182

183

184

185

186

187

188

189

190

191

192

193

194

195

196

197 antimicrobial activity of tedizolid against M. abscessus, alone and combined with other antimicrobials such as clarithromycin and amikacin (40-42). Using a macrophage model, tedizolid was shown to have intracellular antimicrobial activity when used alone, and more so when combined with imipenem with or without avibactam (43). Compared to the oxazolidinone linezolid, tedizolid is reported to have a more favorable tolerability profile in a 14-day treatment regimen (44). Clinical reports of treating M. abscessus infection with tedizolid are extremely limited. Of note, one report described successful tedizolid treatment of an M. abscessus infection in an immunocompromised host (45).

Two recently developed anti-tuberculous drugs - delamanid and pretomanid (PA-824) were evaluated for their anti-bacterial effect on NTMs, although none examined M. abcessus. In a study on Mycobacterium ulcerans, MIC of pretomanid ranged 4 to $16 \mu \mathrm{g} / \mathrm{ml}$, however clinical effect was absent in a mouse-model of infection (46). In study screening antimicrobials for Mycobacterium marinum infection, delamanid, but not pretomanid, was active in vitro, while both reduced bacterial counts and improved survival in a zebrafish in vivo mode.

Several experimental drugs currently in development have been evaluated for their effect on $M$. abscessus: Delpazolid (LCB01-0371) is a novel oxazolidinone currently in Phase II clinical study for treatment of tuberculosis (https://clinicaltrials.gov/ct2/show/NCT02836483). In a study by Kim et al, delpazolid was shown to have an antimicrobial effect against $M$. abscessus in vitro and in an intracellular macrophage model (47). In a murine model of infection using high antimicrobial dosage, delpazolid was more effective than linezolid in the lungs but less effective in the spleen and liver (47). VXc-486 is a novel aminobenzimidazole which targets gyrase B, 
198 being evaluated as an anti-mycobacterial drug (48). VXc-486 was found to potently inhibit 199 growth of $M$. abscessus in vitro (MIC50, $1.0 \mu \mathrm{g} / \mathrm{ml}$, and MIC90, $4.0 \mu \mathrm{g} / \mathrm{ml}$ ). In vivo data on 200 VXc-486's effect on M. abscessus infection is lacking, but its potency was demonstrated in a 201 tuberculosis murine model (48).

PIPD1, [GSK1985270A; 4-(4-chloro-3-(trifluoromethyl)phenyl)-1-(2-methylbenzyl)piperidin-4-

$203 \mathrm{ol}$, is a new piperidinol-based molecule, that acts against mycobacteria by disrupting mycolic 204 acid translocation from the cytoplasm to the periplasmic side of the plasma membrane, disabling 205 the formation of the outer part or mycobacterial cell wall (49). PIPD1 was shown to exhibit 206 potent activity against clinical M. abscessus strains in vitro (MIC of $0.125 \mathrm{mg} / \mathrm{ml}$, bactericidal in 207 time-killing assays), in infected macrophages and in a zebrafish infection model (49). Indole208 carboxamides also act by disrupting mycolic acid transport and production, therefore inhibiting the synthesis of the mycobacterial cell wall (50). Indole-carboxamides were shown to have a strong antibacterial activity against a wide panel of $M$. abscessus isolates in vitro and in infected macrophages (50), were shown to have synergistic effect with imipenem and cefoxitin (51), and

212 were found active in a murine $M$. abscessus infection model (52). No clinical trials are available 213 for these experimental drugs.

\section{Phage therapy}

215 The notion of using phages against bacterial infection has been revisited in the past years as part 216 of the ongoing search for solutions for multi-drug resistant organisms (53). Therapeutic 217 bacteriophages are appealing considering they are pathogen specific, and are safe to human 218 tissues (53). A report of successful bacteriophage treatment of a multi-drug resistant gram219 negative infection has encouraged further studies and clinical trials in this field (54). In 2019, 220 Dedrick et al (55) reported a case of a 15 year old lung-transplant patient who suffered from 
221 disseminated M. abscessus infection, mostly focused to her lungs and skin. The patient received

222 a prolonged treatment of a combination-cocktail of three engineered mycobacriophages, and

223 subsequently cleared the infection. No adverse effects were noted for this treatment (55).

224 Hopeful as it may be, phage therapy for M. abscessus infection is at this point far from being a

225 practical solution. Phage therapy requires personalized engineering of phages along with a large

226 collection of bacteriophages only available in specific research laboratories, making commercial

227 production impractical. In addition, emerging phage-resistance may be a future issue, especially

228 in prolonged treatments (53).

229 Discussion

230 Treating $M$. abscessus infections is extremely challenging due to complex antimicrobial 231 resistance profiles, limited clinical predictability of in vitro results, and failures despite 232 prolonged multi-drug regimens. As part of a global search for therapies for multi-drug resistant 233 bacteria, new antimicrobials and antimicrobial combinations are evaluated in general, and 234 specifically for M. abscessus. Unfortunately, most studies examining these antimicrobial agents 235 are either performed in vitro or in cell or animal models (see table 1). Clinical experience with 236 novel drugs or the optimal drug combinations are scant, leaving physicians to tailor antimicrobial 237 treatment for $M$. abscessus mostly based on MIC values of the bacteria. While there is a dire 238 need for clinical trials comparing treatments, these may be difficult to standardize given the 239 complexity of antimicrobial regimens. In the current medical trend toward personalized 240 medicine, pathogen specific treatment - such as engineered phage therapy, or tailored drug241 combinations according to combined antimicrobial efficacy against a clinical isolate- may be the 242 key to eradication and clinical success. Whether using a tailored or universal guideline approach, 243 clinical studies are needed to aid treatment decisions for these devastating and chronic infections. 


\section{Abbreviations:}

246 NTM - Non-tuberculous mycobacteria

247 BDQ - Bedaquiline

248 BLA $\mathrm{AAB}_{\mathrm{M}}-\beta$ lactamase inhibitor of Mycobacterium abscessus, Ambler-Class A

249 CFZ - Clofazimine

250 CLR - Clarithromycin

251 AMK - Amikacin

252 TIG - Tigecycline

253 VAN - Vancomycin

254 RFB - Rifabutin

255

256 Funding: MM is supported by the Israeli Science Foundation Physician-Researcher Grant 4090.

257 Author Contributions: MM and DB have both conceptualized, drafted and revised this review.

$258 \mathrm{MM}$ and DB both read and agreed to the published version of the manuscript.

259 Acknowledgment: the authors would like to thank Nitzan Meir for technical assistance.

260 Conflicts of Interest: The authors declare no conflict of interest

261 References:

262 1. Daley CL, Iaccarino JM, Lange C, Cambau E, Wallace RJJ, Andrejak C, et al. Treatment 263 of nontuberculous mycobacterial pulmonary disease: an official ATS/ERS/ESCMID/IDSA clinical practice guideline. Eur Respir J. 2020 Jul;56(1).

265 2. Li B, Yang S, Chu H, Zhang Z, Liu W, Luo L, et al. Relationship between Antibiotic 
Susceptibility and Genotype in Mycobacterium abscessus Clinical Isolates. Front Microbiol. 2017;8:1739.

3. Lipworth S, Hough N, Leach L, Morgan M, Jeffery K, Andersson M, et al. WholeGenome Sequencing for Predicting Clarithromycin Resistance in Mycobacterium abscessus. Antimicrob Agents Chemother. 2019 Jan;63(1).

4. Haworth CS, Banks J, Capstick T, Fisher AJ, Gorsuch T, Laurenson IF, et al. British Thoracic Society guidelines for the management of non-tuberculous mycobacterial pulmonary disease (NTM-PD). Thorax. 2017 Nov;72(Suppl 2):ii1 LP-ii64.

5. Floto RA, Olivier KN, Saiman L, Daley CL, Herrmann J-L, Nick JA, et al. US Cystic Fibrosis Foundation and European Cystic Fibrosis Society consensus recommendations for the management of non-tuberculous mycobacteria in individuals with cystic fibrosis. Thorax. 2016 Jan;71 Suppl 1:i1-22.

6. Ruth MM, Sangen JJN, Remmers K, Pennings LJ, Svensson E, Aarnoutse RE, et al. A bedaquiline/clofazimine combination regimen might add activity to the treatment of clinically relevant non-tuberculous mycobacteria. J Antimicrob Chemother. 2019 Apr;74(4):935-43.

7. van Ingen J, Totten SE, Helstrom NK, Heifets LB, Boeree MJ, Daley CL. In vitro synergy between clofazimine and amikacin in treatment of nontuberculous mycobacterial disease. Antimicrob Agents Chemother [Internet]. 2012/10/01. 2012 Dec;56(12):6324-7. Available from: https://pubmed.ncbi.nlm.nih.gov/23027189

8. Singh S, Bouzinbi N, Chaturvedi V, Godreuil S, Kremer L. <em>In vitro</em> evaluation of a new drug combination against clinical isolates belonging to the 

$<\mathrm{em}>$ Mycobacterium abscessus $</ \mathrm{em}>$ complex. Clin Microbiol Infect [Internet]. 2014 Dec 1;20(12):O1124-7. Available from: https://doi.org/10.1111/1469-0691.12780

9. Obregón-Henao A, Arnett KA, Henao-Tamayo M, Massoudi L, Creissen E, Andries K, et al. Susceptibility of Mycobacterium abscessus to antimycobacterial drugs in preclinical models. Antimicrob Agents Chemother. 2015 Nov;59(11):6904-12.

10. Yang B, Jhun BW, Moon SM, Lee H, Park HY, Jeon K, et al. Clofazimine-Containing Regimen for the Treatment of Mycobacterium abscessus Lung Disease. Antimicrob Agents Chemother. 2017 Jun;61(6).

11. Martiniano SL, Wagner BD, Levin A, Nick JA, Sagel SD, Daley CL. Safety and Effectiveness of Clofazimine for Primary and Refractory Nontuberculous Mycobacterial Infection. Chest. 2017 Oct;152(4):800-9.

12. Andries K, Verhasselt P, Guillemont J, Göhlmann HWH, Neefs J-M, Winkler H, et al. A Diarylquinoline Drug Active on the ATP Synthase of \&lt;em\&gt;Mycobacterium tuberculosis\&lt;/em\&gt; Science (80- ) [Internet]. 2005 Jan 14;307(5707):223 LP - 227. Available from: http://science.sciencemag.org/content/307/5707/223.abstract

13. NoThe Use of Bedaquiline in the Treatment of Multidrug-Resistant Tuberculosis: Interim Policy Guidance. Geneva: World Health Organization; 2013. 6, WHO Interim policy recommendations. Available from: https://www.ncbi.nlm.nih.gov/books/NBK154121/ Title.

14. Vesenbeckh S, Schönfeld N, Roth A, Bettermann G, Krieger D, Bauer TT, et al. Bedaquiline as a potential agent in the treatment of Mycobacterium abscessus infections. Vol. 49, The European respiratory journal. England; 2017. 
15. Pang Y, Zheng H, Tan Y, Song Y, Zhao Y. In Vitro Activity of Bedaquiline against Nontuberculous Mycobacteria in China. Antimicrob Agents Chemother. 2017 May;61(5).

16. Lerat I, Cambau E, Roth Dit Bettoni R, Gaillard J-L, Jarlier V, Truffot C, et al. In vivo evaluation of antibiotic activity against Mycobacterium abscessus. J Infect Dis. 2014 Mar;209(6):905-12.

17. Dupont C, Viljoen A, Thomas S, Roquet-Banères F, Herrmann J-L, Pethe K, et al. Bedaquiline Inhibits the ATP Synthase in Mycobacterium abscessus and Is Effective in Infected Zebrafish. Antimicrob Agents Chemother. 2017 Nov;61(11).

18. Philley J V, Wallace RJJ, Benwill JL, Taskar V, Brown-Elliott BA, Thakkar F, et al. Preliminary Results of Bedaquiline as Salvage Therapy for Patients With Nontuberculous Mycobacterial Lung Disease. Chest. 2015 Aug;148(2):499-506.

19. Lindman M, Dick T. Bedaquiline Eliminates Bactericidal Activity of $\beta$-Lactams against Mycobacterium abscessus. Antimicrob Agents Chemother. 2019 Aug;63(8).

20. Aziz DB, Low JL, Wu M-L, Gengenbacher M, Teo JWP, Dartois V, et al. Rifabutin Is Active against Mycobacterium abscessus Complex. Antimicrob Agents Chemother. 2017 Jun;61(6).

21. Ramis IB, Figueiredo R, Ramos DF, Halicki PCB, von Groll A, Viveiros M, et al. Activity of Rifabutin and Hemi-synthetic Derivatives Against Mycobacterium abscessus. Med Chem. 2018;14(4):394-9.

22. Soroka D, Dubée V, Soulier-Escrihuela O, Cuinet G, Hugonnet J-E, Gutmann L, et al. Characterization of broad-spectrum Mycobacterium abscessus class A $\beta$-lactamase. $\mathbf{J}$ 
Antimicrob Chemother [Internet]. 2013 Oct 16;69(3):691-6. Available from: https://doi.org/10.1093/jac/dkt410

23. Dubée V, Bernut A, Cortes M, Lesne T, Dorchene D, Lefebvre A-L, et al. $\beta$-Lactamase inhibition by avibactam in Mycobacterium abscessus. J Antimicrob Chemother. 2015 Apr;70(4):1051-8.

24. Meir M, Bifani P, Barkan D. The addition of avibactam renders piperacillin an effective treatment for Mycobacterium abscessus infection in an in vivo model. Antimicrob Resist Infect Control. 2018;7:151.

25. Lefebvre A-L, Le Moigne V, Bernut A, Veckerlé C, Compain F, Herrmann J-L, et al. Inhibition of the $\beta$-Lactamase Bla(Mab) by Avibactam Improves the In Vitro and In Vivo Efficacy of Imipenem against Mycobacterium abscessus. Antimicrob Agents Chemother [Internet]. 2017 Mar 24;61(4):e02440-16. Available from: https://pubmed.ncbi.nlm.nih.gov/28096155

26. Lopeman RC, Harrison J, Rathbone DL, Desai M, Lambert PA, Cox JAG. Effect of Amoxicillin in combination with Imipenem-Relebactam against Mycobacterium abscessus. Sci Rep [Internet]. 2020;10(1):928. Available from: https://doi.org/10.1038/s41598-020-57844-8

27. Kaushik A, Ammerman NC, Lee J, Martins O, Kreiswirth BN, Lamichhane G, et al. In Vitro Activity of the New $\beta$-Lactamase Inhibitors Relebactam and Vaborbactam in Combination with $\beta$-Lactams against Mycobacterium abscessus Complex Clinical Isolates. Antimicrob Agents Chemother. 2019 Mar;63(3).

28. Kumar P, Chauhan V, Silva JRA, Lameira J, d\&\#039;Andrea FB, Li S-G, et al. \&lt;span 
class=\&quot;named-content genus-species\&quot; id=\&quot;named-content-

1\&quot;\&gt;Mycobacterium abscessus\&lt;/span\&gt; \&lt;span

class $=\& q u o t ; s c \& q u o t ; \& g t ; 1 \& 1 t ; /$ span\&gt;,\&lt;span

class=\&quot;sc\&quot;\&gt;d\&lt;/span\&gt;-Transpeptidases Are Susceptible to

Inactivation by Carbapenems and Cephalosporins but Not Penicillins. Antimicrob Agents

Chemother [Internet]. 2017 Oct 1;61(10):e00866-17. Available from:

http://aac.asm.org/content/61/10/e00866-17.abstract

29. Edoo Z, Iannazzo L, Compain F, Li de la Sierra Gallay I, van Tilbeurgh H, Fonvielle M, et al. Synthesis of Avibactam Derivatives and Activity on $\beta$-Lactamases and Peptidoglycan Biosynthesis Enzymes of Mycobacteria. Chemistry. 2018 Jun;24(32):8081-6.

30. Story-Roller E, Maggioncalda EC, Lamichhane G. Select $\beta$-Lactam Combinations Exhibit Synergy against Mycobacterium abscessus In Vitro. Antimicrob Agents Chemother. 2019 Apr;63(4).

31. Story-Roller E, Maggioncalda EC, Lamichhane G. Synergistic Efficacy of $\beta$-Lactam Combinations against Mycobacterium abscessus Pulmonary Infection in Mice. Antimicrob Agents Chemother [Internet]. 2019 Jul 25;63(8):e00614-19. Available from: https://pubmed.ncbi.nlm.nih.gov/31109979

32. Mukherjee D, Wu M-L, Teo JWP, Dick T. Vancomycin and Clarithromycin Show Synergy against \&lt;em\&gt;Mycobacterium abscessus In Vitro\&lt;/em\&gt; Antimicrob Agents Chemother [Internet]. 2017 Dec 1;61(12):e01298-17. Available from: http://aac.asm.org/content/61/12/e01298-17.abstract 
375 33. Bax HI, de Vogel CP, Mouton JW, de Steenwinkel JEM. Omadacycline as a promising

376

377

378

379

380

381

382

383

384

385

386

387

388

389

390

391

392

393

394 new agent for the treatment of infections with Mycobacterium abscessus. J Antimicrob

Chemother [Internet]. 2019 Jun 24;74(10):2930-3. Available from:

https://doi.org/10.1093/jac/dkz267

34. Solomkin J, Evans D, Slepavicius A, Lee P, Marsh A, Tsai L, et al. Assessing the Efficacy and Safety of Eravacycline vs Ertapenem in Complicated Intra-abdominal Infections in the Investigating Gram-Negative Infections Treated With Eravacycline (IGNITE 1) Trial: A Randomized Clinical Trial. JAMA Surg [Internet]. 2017 Mar 1;152(3):224-32. Available from: https://doi.org/10.1001/jamasurg.2016.4237

35. Kaushik A, Ammerman NC, Martins O, Parrish NM, Nuermberger EL. In Vitro Activity of New Tetracycline Analogs Omadacycline and Eravacycline against Drug-Resistant Clinical Isolates of Mycobacterium abscessus. Antimicrob Agents Chemother [Internet]. 2019 May 24;63(6):e00470-19. Available from:

https://pubmed.ncbi.nlm.nih.gov/30962331

36. Shoen C, Benaroch D, Sklaney M, Cynamon M. In Vitro Activities of Omadacycline against Rapidly Growing Mycobacteria. Antimicrob Agents Chemother [Internet]. 2019 Apr 25;63(5):e02522-18. Available from: https://pubmed.ncbi.nlm.nih.gov/30858221

37. Gallagher JC. Omadacycline: A Modernized Tetracycline. Vol. 69, Clinical infectious diseases : an official publication of the Infectious Diseases Society of America. 2019. p. S1-5.

38. Tanaka SK, Steenbergen J, Villano S. Discovery, pharmacology, and clinical profile of omadacycline, a novel aminomethylcycline antibiotic. Bioorg Med Chem. 2016 
Dec;24(24):6409-19.

398

399

400

401

402

403

404

405

406

407

408

409

410

411

412

413

414

415

416

417

39. Minhas R, Sharma S, Kundu S. Utilizing the Promise of Omadacycline in a Resistant, Non-tubercular Mycobacterial Pulmonary Infection. Vol. 11, Cureus. 2019. p. e5112.

40. Tang YW, Cheng B, Yeoh SF, Lin RTP, Teo JWP. Tedizolid Activity Against Clinical Mycobacterium abscessus Complex Isolates-An in vitro Characterization Study. Front Microbiol. 2018;9:2095.

41. Compain F, Soroka D, Heym B, Gaillard J-L, Herrmann J-L, Dorchène D, et al. In vitro activity of tedizolid against the Mycobacterium abscessus complex. Diagn Microbiol Infect Dis. 2018 Mar;90(3):186-9.

42. Ruth MM, Koeken VACM, Pennings LJ, Svensson EM, Wertheim HFL, Hoefsloot W, et al. Is there a role for tedizolid in the treatment of non-tuberculous mycobacterial disease? J Antimicrob Chemother. 2020 Mar;75(3):609-17.

43. Le Run E, Arthur M, Mainardi J-L. In Vitro and Intracellular Activity of Imipenem Combined with Tedizolid, Rifabutin, and Avibactam against Mycobacterium abscessus. Antimicrob Agents Chemother. 2019 Apr;63(4).

44. Shorr AF, Lodise TP, Corey GR, De Anda C, Fang E, Das AF, et al. Analysis of the phase 3 ESTABLISH trials of tedizolid versus linezolid in acute bacterial skin and skin structure infections. Antimicrob Agents Chemother. 2015 Feb;59(2):864-71.

45. Seki M, Kamioka Y, Takano K, Imai H, Shoji M, Hariu M, et al. Mycobacterium abscessus Associated Peritonitis with CAPD Successfully Treated Using a Linezolid and Tedizolid Containing Regimen Suggested Immunomodulatory Effects. Am J Case Rep 
[Internet]. 2020 Jun 29;21:e924642-e924642. Available from: https://pubmed.ncbi.nlm.nih.gov/32598338

46. Ji B, Lefrançois S, Robert J, Chauffour A, Truffot C, Jarlier V. In vitro and in vivo activities of rifampin, streptomycin, amikacin, moxifloxacin, R207910, linezolid, and PA824 against Mycobacterium ulcerans. Antimicrob Agents Chemother. 2006 Jun;50(6):1921-6.

47. Kim TS, Choe JH, Kim YJ, Yang C-S, Kwon H-J, Jeong J, et al. Activity of LCB01-0371, a Novel Oxazolidinone, against Mycobacterium abscessus. Antimicrob Agents Chemother. 2017 Sep;61(9).

48. Locher CP, Jones SM, Hanzelka BL, Perola E, Shoen CM, Cynamon MH, et al. A novel inhibitor of gyrase B is a potent drug candidate for treatment of tuberculosis and nontuberculosis mycobacterial infections. Antimicrob Agents Chemother. 2015 Mar;59(3):1455-65.

49. Dupont C, Viljoen A, Dubar F, Blaise M, Bernut A, Pawlik A, et al. A new piperidinol derivative targeting mycolic acid transport in Mycobacterium abscessus. Mol Microbiol. 2016 Aug;101(3):515-29.

50. Kozikowski AP, Onajole OK, Stec J, Dupont C, Viljoen A, Richard M, et al. Targeting Mycolic Acid Transport by Indole-2-carboxamides for the Treatment of Mycobacterium abscessus Infections. J Med Chem. 2017 Jul;60(13):5876-88.

51. Raynaud C, Daher W, Roquet-Banères F, Johansen MD, Stec J, Onajole OK, et al. Synergistic Interactions of Indole-2-Carboxamides and $\beta$-Lactam Antibiotics against Mycobacterium abscessus. Antimicrob Agents Chemother. 2020 Apr;64(5). 
440 52. Pandya AN, Prathipati PK, Hegde P, Li W, Graham KF, Mandal S, et al. Indole-2-

441

442

443

444

445

446

447

448

449

450

451

452

453

454

455

456

457

458

459
Carboxamides Are Active against Mycobacterium abscessus in a Mouse Model of Acute Infection. Antimicrob Agents Chemother. 2019 Mar;63(3).

53. Azimi T, Mosadegh M, Nasiri MJ, Sabour S, Karimaei S, Nasser A. Phage therapy as a renewed therapeutic approach to mycobacterial infections: a comprehensive review. Infect Drug Resist. 2019;12:2943-59.

54. Schooley RT, Biswas B, Gill JJ, Hernandez-Morales A, Lancaster J, Lessor L, et al. Development and Use of Personalized Bacteriophage-Based Therapeutic Cocktails To Treat a Patient with a Disseminated Resistant Acinetobacter baumannii Infection. Antimicrob Agents Chemother [Internet]. 2017 Sep 22;61(10):e00954-17. Available from: https://pubmed.ncbi.nlm.nih.gov/28807909

55. Dedrick RM, Guerrero-Bustamante CA, Garlena RA, Russell DA, Ford K, Harris K, et al. Engineered bacteriophages for treatment of a patient with a disseminated drug-resistant Mycobacterium abscessus. Nat Med [Internet]. 2019;25(5):730-3. Available from: https://doi.org/10.1038/s41591-019-0437-z 
Table 1

462

Therapy

In vitro evidence

In vivo models

Published Clinical

Experience

\begin{tabular}{|c|c|c|c|}
\hline Clofazimine & $\begin{array}{l}\text { Synergy with CLR, AMK, TIG } \\
\text { and BDQ }(6,7)\end{array}$ & $\begin{array}{l}\text { Treatment of } M . \text { abscessus } \\
\text { in } \mathrm{GKO}^{-/-} \text {and SCID mice } \\
\text { with a combination of CFZ } \\
\text { and BDQ was effective (9). }\end{array}$ & $\begin{array}{l}\text { Retrospective study } \\
\text { of } 42 \text { patients (10), } \\
\text { Cohort study in } \\
\text { immunocompromise } \\
\text { d patients. (11) }\end{array}$ \\
\hline $\begin{array}{l}\text { Bla }{ }_{\text {Mab }} \text { inhibitors } \\
\text { Avibactam } \\
\text { Relebactam } \\
\text { Vaborbactam }\end{array}$ & $\begin{array}{l}\text { Active against reference and } \\
\text { clinical isolates when combined } \\
\text { with } \beta \text {-lactams }(24,27,43) \text {. }\end{array}$ & $\begin{array}{l}\text { Avibactam combinations } \\
\text { effective in macrophage, } \\
\text { Zebrafish, and Galleria } \\
\text { mellonella models }(23,24) .\end{array}$ & N/A \\
\hline Dual $\beta$-lactams & $\begin{array}{l}\text { Synergy of two } \beta \text {-lactams shown } \\
\text { in reference and clinical strains } \\
\text { (30) }\end{array}$ & $\begin{array}{l}\text { Synergy in a murine model } \\
\text { of chronic pulmonary } \\
\text { infection ( } 31 \text { ) }\end{array}$ & N/A \\
\hline Bedaquiline & $\begin{array}{l}\text { Activity in vitro in clinical strains } \\
\text { (17) } \\
\text { Possible antagonism with } \beta \text { - } \\
\text { lactams(19) }\end{array}$ & $\begin{array}{l}\text { Effect of CFZ/BDQ in } \\
\mathrm{GKO}^{-1-} \text { and SCID mice(9). } \\
\text { No effect in nude mice (16), } \\
\text { Protective effect in } \\
\text { zebrafish(17). }\end{array}$ & $\begin{array}{l}\text { Report of } 10 \\
\text { patients, favorable } \\
\text { tolerability }(18)\end{array}$ \\
\hline VAN/CLA combination & $\begin{array}{l}\text { Synergy of VAN and CLR in } \\
\text { reference and clinical strains, } \\
\text { questionable effect in strains with } \\
\text { acquired CLR resistance (32). }\end{array}$ & N/A & N/A \\
\hline Rifabutin & $\begin{array}{l}\text { Activity against clinical and } \\
\text { reference strains, including CLR } \\
\text { resistant strains }(20,21)\end{array}$ & N/A & N/A \\
\hline $\begin{array}{l}\text { Omadacycline, } \\
\text { Eravacycline }\end{array}$ & $\begin{array}{l}\text { omadacycline }(33,36) \text { and } \\
\text { eravacycline }(34,35) \text { have activity } \\
\text { against reference and clinical } \\
\text { strains }\end{array}$ & N/A & $\begin{array}{l}\text { Report of one } \\
\text { patient - noted } \\
\text { clinical } \\
\text { improvement (39) }\end{array}$ \\
\hline Tedizolid & $\begin{array}{l}\text { Tedizolid has in vitro alone and } \\
\text { combined with CLR and AMK } \\
(40,41)\end{array}$ & $\begin{array}{l}\text { Intracellular effect in a } \\
\text { macrophage model ( } 43 \text { ). }\end{array}$ & $\begin{array}{l}\text { Report of one } \\
\text { immunocompromise } \\
\text { d patient (45) }\end{array}$ \\
\hline Delpazolid & $\begin{array}{l}\text { Active against reference strain and } \\
8 \text { clinical strains. Noted } \\
\text { spontaneous resistance to } \\
\text { delpazolid (47) }\end{array}$ & $\begin{array}{l}\text { Intracellular effect in a } \\
\text { macrophage model (47) } \\
\text { Comparable effect of } \\
\text { delpazolid to linezolid in a } \\
\text { murine model (47). }\end{array}$ & \\
\hline VXc-486 & $\begin{array}{l}\text { Active against multiple strains of } \\
\text { M. abscessus }\end{array}$ & N/A & N/A \\
\hline PIPD1 & Activity against clinical strains(49) & $\begin{array}{l}\text { Intracellular effect in } \\
\text { macrophages, effective in a } \\
\text { zebrafish model(49). }\end{array}$ & N/A \\
\hline Indole-carboxamides & $\begin{array}{l}\text { Activity against clinical strains }(50) \\
\text { Synergy with imipenem and } \\
\text { cefoxitin (51) }\end{array}$ & $\begin{array}{l}\text { Intracellular effect in } \\
\text { macrophages(50), effect in a } \\
\text { murine model (52). }\end{array}$ & N/A \\
\hline Phage therapy & $\begin{array}{l}\text { Profound use in mycobacterial } \\
\text { laboratory research }\end{array}$ & N/A & $\begin{array}{l}\text { Treatment of } \\
\text { disseminated }\end{array}$ \\
\hline
\end{tabular}


463 Table 1: Experimental therapies of Mycobacterium abscessus infections - Evidence summary.

464 Clofazimine - CFZ, Clarithromycin - CLR, Amikacin -AMK, Tigecycline - TIG, Bedaquiline - BDQ, Vancomycin 465 VAN, Rifabutin - RFB 